\title{
Access and Participation in Quality Education Through Pancasila Shaped Online Interregional Indonesia Teachers Conversations (PSOIITC) Pancasila Inspired Teacher Learning Approach
}

\author{
Christine Pheeney ${ }^{1, *}$
}

\author{
${ }^{1}$ College of Education, Charles Darwin University, Darwin, Australia \\ ${ }^{*}$ Corresponding author. Email: christineida@ozemail.com.au
}

\begin{abstract}
The 2030 Sustainable Development Goals put attention to the children to have equal access and participation in quality education around the world. In Indonesia, Pancasila provides appropriate sociocultural guideline. Pancasila was born from diversity and it becomes a tool to create a good relationship of society towards unity. This study introduces a study about teacher learning inspired by Pancasila. Twenty-three Indonesian teachers, who have diversity of ethnics and religions, were involved in a sixweek program. The investigated conducted by Conflict Resolution Education Module in video and community facilitators involved via online forum. The analysis of teachers' reflections showed they had a maturity concept of unity of diversity achieved by experiential learning through conversation. This is done to expand networking and responsibility and to get an affordable cost of classroom application with large capacities and broad foci. The approach offers input to rethink and reconceptualise of teacher professional development strategies for developing a peaceful nation.

Keywords: Indonesia, Pancasila, teacher learning, unity in diversity
\end{abstract}

\section{INTRODUCTION}

\subsection{Worldwide Access and Participation Agenda, Relevant Research and Activities}

The 2030 Sustainable Development Goals have attention to the children's needs/to having equal access and participation in quality education. Teachers are supposed to facilitate students in increasingly diverse classrooms (Ede, 2005). Respect and inclusivity are needed to achieve the objectives, so international education identifies aspects and strategies for effective teaching learnings. Developing 'communities of practice' is discussed by Lave and Wenger (1991) argues Communities of Practice (CoP) as a process of learning occurs in social situations, where structured participation frameworks can provide great conditions to engage participants. Söderström, Hamilton, Dahlgren, and Hult (2006) purposedto develop teacher participation. Progressively, 'collaborative inquiry' is increasingly used internationally in education research practice, where teachers work together with same ideas to discuss and analyse relevant information to utilise insight gained in teaching activities (David, 2009). Concurrently, within postcolonial and transformative learning discourses, collaborative inquiry is commended for facilitating learning that validates and is more inclusive of diversity (Kumar, 2009; Kasl \& Yorks, 2002) and transforming problematic frames of reference (Taylor \& Cranton, 2012). Successively digital connectivity tools emerge offering broad accessibility with facility to develop collaborative communities and maximise reflective opportunities (Garrison, 2006). Garrison (2012) asserts commitment to personal reflection and critical discourse are inherent in community inquiries and produce gains of metacognitive awareness through sustained discourse.

\subsection{Indonesian Inspiration and Opportunity}

Within the Indonesian context, Pancasila provides sociocultural guidelines of appropriate access and participation goals. Pancasila esteems a 'Unity in Diversity' ideal, which recognises Indonesia's diverse constituency and prescribes a social process of deliberative inquiry unifying interdependent relations. Mental Revolution initiatives direct Education institutions to revitalise Pancasila, instructing teachers to revive Pancasila in everyday practices (Secretary Office Mental Revolution, 2016). Aware of challenges in providing teacher professional development to a vast and dispersed population, researcher investigated a potential of social media to support teacher learning of local Indonesian wisdom with interregional 
mutual mentoring, and found great potentials awaiting activation (Pheeney, 2013). Cognisant of international education discussion (overviewed above) that prescribes use of frameworks to engage teacher participation and learning, the Conflict Resolution Education Module CREM (Setiadi, Rohayani \& Pheeney, 2017) was developed. CREM provides input from academics and practitioners sharing classroom strategies, with tools, questions and multi-media animations. Specifically, the module was designed to scaffold Indonesian teachers in an online interregional collaborative inquiry of Pancasila, to enact and lead to revive Pancasila in classrooms.

\subsection{Research and Study Focus}

Against this background, doctoral research engaging and studying Pancasila Shaped Online Interregional Indonesia Teachers Conversations (PSOIITC) was undertaken. The conversations were scaffolded by CREM and the author as human facilitator and researcher. The research question posed is: "What happens when culturally and religiously diverse \& regionally dispersed Indonesian teachers engage in Pancasila Narrative conversations, via Social Media on their phones?". Study of the teachers' experiences explored the relations and processes involved in the inquiry and Pancasila interpretation with a Pragmatic Research Paradigm (PRP). This study overviews PSOIITC sequence of inquiry and themes in teachers' interpretative processing. Quotes from teacher's reflections are shared to reveal the maturation of conceptual knowledge of 'Unity in Diversity' that brought forth relational pedagogy. Awareness of the conversation themes and ensuing Pancasila interpretation is useful to promote discussion in education to rethink and reconceptualise teacher learning with inclusive strategies inspired by Pancasila, towards meeting access and participation goals of quality education.

\section{METHOD}

\subsection{Ethical Foundation}

To engage the PSOIITC and to investigate the teachers' experiences, the approach taken was explicitly guided by the Indonesian socio-culturalism 'gotong royong'. Gotong royong is described as a cooperative, community attitude and service that jointly shoulders responsibilities and shares resources for interdependent relational living (Koentjaraningrat, 1967). In the PSOIITC teachers' 'service' is orientated (and thus studied) around 'Deliberative inquiry reaching Social Justice'. This service is directly inspired by Pancasila's fourth sila: 'A democratic life led by wisdom of thoughts in deliberation amongst representatives of the people'; and fifth phrase translated as: 'Social justice for all people of Indonesia' (Directorate of Foreign Information Services, 1995). This approach correlates to internationally discussed 'collaborative inquiry' methods that outline 'reciprocity' and 'authenticity' principles to govern activities (Bridges \& McGee, 2011). These principles are considered analogous to gotong royong. Accordingly, recruitment and participation - including core sequence of activities, recording, analysis and sharing of research are designed to facilitate mutual sharing of power, valuing of expertise and generating genuine understanding of the experiences (Bridges \& McGee, 2011).

\subsection{Recruitment}

Engaging diverse teacher participation was organised in conjunction with partners in regional locations of twelve dispersed Indonesian provinces [Aceh, Sumatra Utara, Kalimantan Barat, Kalimantan Tengah, Bantan, Jawa Barat, Jawa Timur, Sulawesi Selatan, Bali, Maluku, Nusa Tenggara Timur, Papua - ensuring representation of each geophysical region]. Regional partners were asked to gather teachers representational of diverse ethnicities, religions, age, early to late teaching career, gender, indigenous and transmigrants and from varying school sectors (Government, Private and Tribal) in their region, to hear a presentation of the inquiry opportunity. At each location after giving an overview of PSOIITC aims and activities, voluntary participation committed to engage in inquiry activities was requested (at most sites presentation was by physical presence. Papua presentation was via skype, abiding by Indonesia's Ministry of Research and Technology -RISTEKDIKTI- permit). Participation agreement includes: a) willingness to use personal internet capable mobile device; b) commitment to participate in the collaborative inquiry; and c) act constructively aligned to gotong royong ethos. The study aimed for two groups of ten teachers, including the researcher in roles of facilitator and co-inquirer in each group. Upon agreement, the researcher assisted with setting up google hangouts (google hangouts is a social media application) on teacher's phone/device. Teachers had freedom to withdraw anytime without any consequence by themselves. This freedom was exercised and was reflected in overall recruitment (signed agreements) of twenty-three teachers, fluctuating for various reasons to reach the research goal of eighteen to be co-inquirers with researcher (The researcher has lived cross-culturally in Indonesia over fourteen years, during this time develops cultural understanding and adequate conversational fluency in Bahasa Indonesia, that was employed in design, recruitment, facilitating PSOIITC sessions and forums, interview and survey). While discussing, sharing and reporting options of the study, the 
teachers considered use of their names (first names as used in online conversations) as appropriate and to express joys in the collaborative creations and shared resources being used/shared by each other for classroom teaching and learning, and research. This reflected relational authenticity and reciprocity principles being applied. Similarly, the research undertaking reflected researcher's commitment to gotong royong to contribute times, ideas and expertises to community strengthening.

\subsection{Participation}

Collaborative inquiry in synchronous and asynchronous forums, was scaffolded by CREM (Setiadi et al., 2017), involved the researcher as facilitator and co-inquirer. CREM provided conversation stimulus for four synchronous sessions that were scheduled as one hour per week for four weeks, outside formal teaching hours (a Tuesday group and a Thursday group). Given three time zones across Indonesia, this was earlier or later in the day relating to location. Scheduling became problematic for some teachers in several weeks with spontaneously arising commitments. Resultantly most synchronous sessions were scheduled four times with flexibility for attendance. Adaptable group composition and exchange were supported in asynchronous forums where teachers could ask and respond to each other questions, post and access resources and responses in convenient times. Participation within asynchronous forums also facilitated communication of session details and development of an accessible library that shared videos and photos as well as explanations. The participants were requested to attend a asynchronous forum for one hour.

\subsection{Core Sequence of Activities}

A variety of activities of PSOIITC participation can be seen at Fig. 1 which presents core sequence and key activities. Typically, deliberations or collaborations were contributed 'yarning circle' style - teachers were introduced to or themselves prompted a question, each having opportunity to respond with, ask or be asked further explanation or share similarities or contrasts to their own experiences (Bessarab \& Ng'andu, 2010).

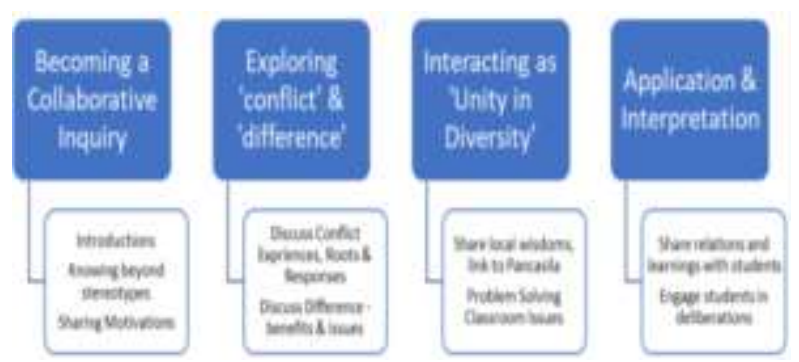

Figure 1 PSOIITC Core Sequence and Key Activities

\subsection{Reflexivity}

After participating in synchronous and asynchronous sessions/forums, teachers completed an online survey and interview to provide an opportunity for reflexivity. The use of both survey and interview was employed to ensure teachers had time to think about their responses and to share ideas freely. Overall with joining recruitment gathering, four weekly synchronous sessions (accompanied by interaction in asynchronous forum), survey and interview of teachers were actively engaged around for two hours per week over six weeks.

\subsection{Recording, Analysis and Sharing of Research}

The synchronous sessions were recorded and linked to the recordings provided to teachers. In interviews, the teachers informed that having links to the sessions was useful for sharing with their students and viewing if they were unable to join a session. This was particularly happened to Siti who had problems with connecting into the online video conference call. It was not clear what the technical difficulties were as she used the same software with the researcher at that times. The asynchronous forum was similarly available for the teachers' access (with closed group status inhibiting use by non-members). The surveys and session dialogue were discussed in interviews. These were recorded and transcribed (by external native Indonesian speaker transcriber). The interview transcripts were available for teachers. Then, the researcher was in contact to undertake member checking during analysis. Frequently, the researcher cooperated with Indonesian counterpart (appreciated provision in RISTEKDIKTI protocols) in connecting to socio-cultural understandings. Analysis of PSOIITC interactions was undertaken with PRP. Pragmatism emphases 'identifying and addressing specific social problems that emerge from society itself' (Morgan, 2014) and is considered appropriate to this study - responding to social issue of teachers by providing equitable access and engaging participation of children; identifying experiential learning and engaging deliberations to explore Pancasila. Pragmatism directs to 
processes and relations relating to a continual interaction of belief and action. Transcripts from PSOIITC sessions and forums, survey and open- ended interview questions were selected to explore details and factors related to teachers' processing experiences and interpretations. The teachers' voices advance knowledge of PSOIITC experience, aligned to authenticity principle/ gotong royong foundation. However, it must be noted that teachers' recruitment from diverse backgrounds was a feature of the research design to enable diversity engagement. Then, subjectivities of each teacher's experience were not intended for generalisations - it was a limited sample. The study explored Indonesian teachers' experiences, in this PSOIITC. Sharing of research results was done with teachers' permission.

\section{FINDINGS AND DISCUSSION}

Teachers engagement in the core sequence (Fig. 1) led to thinking and pedagogy transformation. Various processes were identified as contributing to what can be described as a maturing concept of 'Unity in Diversity' Fig. 2, shows core processes linked to core sequence with activities and contributories.
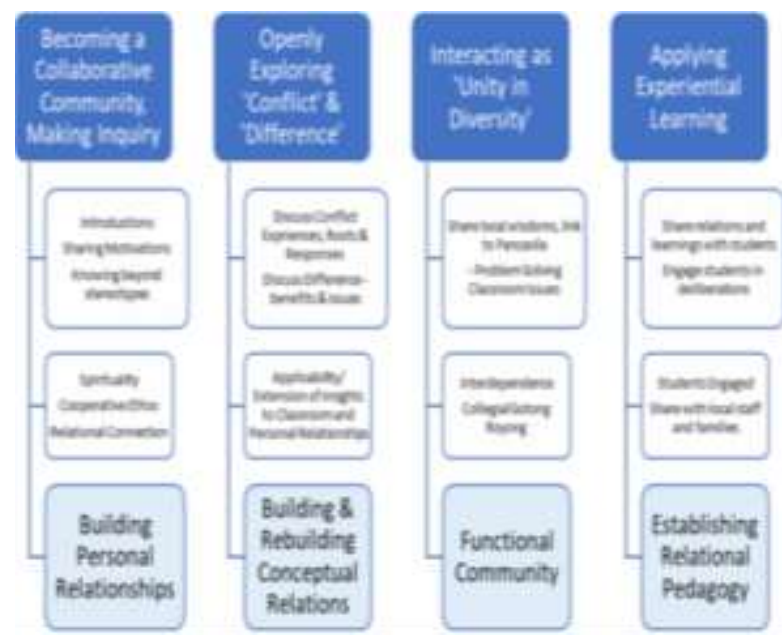

Figure 2 Core processes from core sequence, with activities and contributories

Teachers' cooperative ethos and readiness could build a relationship and rebuild of personal and conceptual knowledge. This foundation produced a sense of community as functional 'Unity in Diversity' - they had a unified goal to inquire and learn from diversity. In this context they acquired experiential learning that employed to deliver relational pedagogy in their classrooms. A selection of reflections from interviews was included here, these reflections revealed that teachers' processing and transforming were expressed of experiences through conversations.

\subsection{Teacher Reflections}

"Previously I didn't really understand (how to teach about Pancasila). Even though we are teachers, we're time pressured and don't have enough details or good ways to explain and make Pancasila a daily expression. So, materials are packed into books and the information seems to go around in circles. Since joining with the other friends and hearing stories, I come to understand what Pancasila is really about. Now we tell the children Pancasila values are within us when we live our everyday life with gotong royong in our environment". (Yoes - Aceh, Muslim, 27, Banda Aceh)

"The conversations had significant impact on my life, I'm happy and enriched - actually (I feel) fully alive when part of this group, sharing and exchanging ideas and finding solutions with the other teachers. For me the conversations were very helpful for my identity- I more deeply know our national culture and composition by archipelago friends sharing”. (Iwan - Sunda, Protestant, 36, Toraja)

"We're told 'diversity is beautiful'. But if you don't know each other there is no respect or kindness, no development of understanding or compassion. I didn't realise we didn't know each other. Thankfully, now, we've known". (Intan (Sunda, Muslim, 40, Tasikmalaya)

"Before I didn't pay much attention to Pancasila even though I am an Indonesian citizen. I thought Pancasila was only a policy guideline, symbol of the Republic, always recited at school. From many examples I have learned in this group, chatting as friends from several regions of the archipelago, now I think Pancasila holds very important guidance. Because as teachers, we are dealing with children of different backgrounds. Actually, (Ifound) Pancasila even relates to family, and can guide healthy interactivity with different personalities. Previously I never thought Pancasila could affect personal life. After I joined, I started thinking of Pancasila benefits to our daily lives. It (Pancasila) can be motivational to how we talk, love and behave with others. Every phrase - one to five is relevant to our lives. It can help us in everything,

For example: In everyday teaching, sometimes there is a conflict in my class. Previously, I have constantly nagged the students to behave. But I learnt with the archipelago teachers I need to get to know my students and I learnt ways to engage, ask and find out about students' diverse 
backgrounds and meanings ascribed and I learnt the impact of heritages. Now I am more focused on taking care of how I act and discipline them, being responsive to them". (Agustina - Waropen, Protestant, 34, Jayapura).

"I have previously joined a Pancasila teacher training event; it wasn't very deep. We just sat on a school bench and heard a theoretical presentation. This activity is different, in the way we did things - we joined others from very far places and didn't know them at first. And our contact was via technology. We built relationships between us. We discussed Pancasila linked to reality and experiences of life. By doing so, now I know more about the theory of Pancasila, I have practiced it as life". (Yoni - Bali, Hindu, 22, Denpasar).

"Typically, Unity in Diversity is almost always forgotten by teachers who don't remember how to provide an example to students. This experience has greatly opened my thinking, transforming my beliefs, opinions and hopes. I've changed, for the better. It turns out if we apply Pancasila meanings, by engaging children and interacting with them, together we passionately support one another to live out Pancasila. I hope it doesn't finish here and isn't limited to these people only. I believe those who understand Pancasila can really live peacefully". (Darma - Batak, Protestant, 36, Medan).

"Our sessions are practical; I use the exchanges and share the experiences with my class. The students see an example of everyone from different backgrounds sharing. It became a way for us to organise classroom situations, to have discussions among friends". (Feni - Tionghoa, Buddhist, 27, Pontianak).

\subsection{Brief Comment}

In these teachers' reflections, researcher got a glimpse of PSOIITC impacts to their personal and professional beliefs and action. The teachers articulated the experience as a form of transformation. Then, it helped them to enrich their interpretation and application of Pancasila, attributing this to 'learning from friends'. 'Learning from friends' in line with Aman's (2013) findings, he explained that mentoring allows understandings development as obligations and recognitions to others

Wants to be 'known' and 'know' was a theme evident in the teachers' expressed (and shared) motivations to join and engage in PSOIITC. Gotong royong and deliberations in conversations enabled building and rebuilding of interpersonal and conceptual relationships. Furthermore, a functional community of teachers was available to share and to apply learnings with their respective classes and local communities. It strongly clear that relational and experiential learning were essential to enable maturation of 'Unity in Diversity' conception and relational pedagogy. The teachers' openness and willingness to engage, share and learn from each other were done to provide equitable access and participation for their students. This is an evidence that teachers spend their time and resources voluntarily without payment as a basis of interpretation of Pancasila.

Further details of human computer interactions facilitating PSOIITC learning are described in open access article 'Harnessing Digital Tools in Collaborative Inquiry for Contemporary Interpretation of the Pancasila' (Pheeney, 2019). Deeper exploration of the teachers' experiences and aspects that support and/or hinder contemporary interpretation of PSOIITC are being described in the researcher's current dissertation.

\section{CONCLUSION}

This study introduced an issue of Pancasila that inspired approach of teacher learning. It can be summarised as Pancasila Shaped Online Interregional Indonesia Teachers Conversations (PSOIITC). Teachers representative of Indonesia's diverse ethnic and religious backgrounds in dispersed locations were involved in a six-week online program. Deliberative inquiry was scaffolded by Conflict Resolution Education Module video materials, a community facilitator, synchronous and asynchronous forums. Teacher reflections showed their concept 'Unity in Diversity' through experiential learning in conversational processing. Moreover, social media utilization for teacher learning is able to facilitate a deeper understanding of Pancasila. PSOIITC facilitated teachers to interact, collaborate, learn develop cultural literacies, share resources and adapt existing education structures transparently among teachers and stakeholders. Interaction that carried out through social media helped teachers to respond to the challenges and to build a proper synergy. This is intended to revive the values of Pancasila. Interregional interactions conducted online provide a number of benefits for teachers, among which are affordable costs and able to reach teachers broadly, with capacities that can benefit widely and to develop other foci. Teachers contributed two hours per week for six weeks by using existing resources. However, teachers are encouraged to pay attention of time during collaborative investigation. Besides, the utilization of community facilitators during this activity is advisable. The PSOIITC approach offers input for rethinking and is conceptualized as a form of teacher's professional development strategy for peaceful national development. 


\section{ACKNOWLEDGMENT}

Thanks to the teachers who participated in this research and to supervisors and staff at RISTEKDIKTI, UPI, CDU and regional partners who have been assisting, thus this research could be done well.

\section{REFERENCES}

Aman, R. (2013). Bridging the gap to those who lack: intercultural education in the light of modernity and the shadow of coloniality. Pedagogy, Culture \& society, 21(2), 279-297.

Bessarab, D., \& Ng'andu, B. (2010). Yarning about yarning as a legitimate method in Indigenous research. International Journal of Critical Indigenous Studies, $3(1), 37-50$.

Bridges, D. \& McGee, S. (2011). Collaborative inquiry. In Creative spaces for qualitative researching (pp. 213222). Sense Publishers.

David, J. (2009). Collaborative inquiry. Educational Leadership, 66(4), 87-88.

Directorate of Foreign Information Services. (1995). Indonesia 1996: An official handbook. Jakarta: Perum Percetakan Negara RI. Retrieved from: http://www.indonezia.ro/republic.htm

Ede, S. (2005). Art and science. London: I. B. Tauris, London. ISSBN: 1850435839. Retrieved from https://olin.tind.io/record/128235/.

Garrison, D. (2006). Online collaboration principles. Journal of Asynchronous Learning Networks, 10(1), 2534.

Garrison, D. (2012). Article review - Social presence within the community of inquiry framework. The International Review of Research in Open and Distributed Learning, 13(1), 250-253.

Kasl, E., \& Yorks, L. (2002). An extended epistemology for transformative learning theory and its application through collaborative inquiry. Teachers College Record, 2, 1-17.

Koentjaraningrat. (1967). Modern Indonesia project. Villages in Indonesia. New York: Cornell University Press.

Kumar, M. (2009). Postcolonial theory and crossculturalism: Collaborative 'signposts' of discursive practices. The Journal of Educational Enquiry, 1(2), 82-92.

Lave, J. \& Wenger, E. (1991). Situated learning: Legitimate peripheral participation. Oakleigh, Vic: Cambridge University Press.

Morgan, D. L. (2014). Pragmatism as a paradigm for social research. Qualitative Inquiry, 20(8), 1045-1053.

Pheeney, C. (2013). The potential of social media to support teachers in Aceh, Indonesia, in Professional Learning to Effectively Implement Local Content Initiatives, Master of Education Dissertation.

Pheeney, C. (2019, April). Harnessing digital tools in collaborative inquiry for contemporary interpretation of the Pancasila. In Proceedings of the 5th International ACM In-Cooperation HCI and UX Conference (pp. 128-136). ACM.

Secretary Office Mental Revolution. (2016). Character education as a base for mental revolution. Press Release. Retrieved from http://revolusimental.go.id/warta/berita

Setiadi, E., Rohayani, I. \& Pheeney, C. (2017). Modul pendidikan resolusi konflik: Modul pembelajaran guru profesional. Bandung, Indonesia. Nomor: EC00201802698

Söderström, T., Hamilton, D., Dahlgren, E., \& Hult, A. (2006). Premises, promises: Connection, community, and communion in online education. Discourse: Studies in the Cultural Politics of Education, 27(4), 533-549.

Taylor, E. W., \& Cranton, P. (2012). The handbook of transformative learning: Theory, research, and practice. John Wiley \& Sons. 